\title{
Advances in ${ }^{15} \mathrm{~N}$-tracing experiments: new labelling and data analysis approaches
}

\author{
Tobias Rütting*1, Dries Huygens†‡, Jeroen Staelens† $\$$, Christoph Müller $\| \uparrow$ and Pascal Boeckx† \\ "Department of Plant and Environmental Sciences, University of Gothenburg, Box 461, 40530 Gothenburg, Sweden, †laboratory of Applied Physical \\ Chemistry, ISOFYS, Ghent University, Coupure 653, 9000 Ghent, Belgium, łFaculty of Agricultural Sciences, Universidad Austral de Chile, Independencia 641, \\ Valdivia, Chile, §laboratory of Forestry, Ghent University, Geraardsbergsesteenweg 267, 9090 Gontrode, Belgium, ॥Department of Plant Ecology, \\ Justus-Liebig-University Giessen, Heinrich-Buff-Ring 26, 35385 Giessen, Germany, and School of Biology and Environmental Sciences, University College \\ Dublin, Belfield, Dublin 4, Ireland
}

\begin{abstract}
To obtain an in-depth understanding of soil nitrogen dynamics, it is necessary to quantify a variety of simultaneously occurring gross nitrogen transformation processes. In order to do so, most studies apply ${ }^{15} \mathrm{~N}$ in a disturbed soil-microbial-root system and quantify gross rates based on the principles of ${ }^{15} \mathrm{~N}$ isotope dilution. However, this approach has several shortcomings. First, studying disturbed soil provides only limited information on in situ soil nitrogen dynamics. Secondly, the analytical data analysis allows the quantification of total production and consumption rates of the labelled pool, but does not provide information on processspecific transformation rates. Combining in situ ${ }^{15} \mathrm{~N}$ isotope labelling over $1-2$ weeks with numerical data analysis allows determining process-specific gross nitrogen transformations in undisturbed soils under field conditions in the presence of live roots and their associated microbial communities. This has the potential to increase our understanding of nitrogen dynamics in the soil environment.
\end{abstract}

\section{In situ ${ }^{15} \mathrm{~N}$ labelling}

Measurements of gross nitrogen dynamics are commonly made by ${ }^{15} \mathrm{~N}$ isotope dilution studies. The principle of the isotope dilution technique is based on the dilution of the product pool that has been labelled with ${ }^{15} \mathrm{~N}$, such as ammonium $\left(\mathrm{NH}_{4}{ }^{+}\right)$or nitrate $\left(\mathrm{NO}_{3}{ }^{-}\right)$[1]. Three experimental set-ups with various degrees of rhizosphere distortion are often used to assess gross nitrogen transformations: (i) laboratory incubations of fully disturbed soils, i.e. after mixing, drying, sieving, storing and/or root-picking of the soil (e.g. [2]), (ii) laboratory incubations of intact fieldcollected soil cores, eventually after a short cold storage period (e.g. [3]) and (iii) in situ incubations of introduced soil cores (e.g. [4]). All three set-ups may provide valuable information since they can be used to derive potential gross nitrogen transformations and to assess the influence of external drivers on soil nitrogen dynamics. Nevertheless, the study set-ups are known to alter factors that influence soil nitrogen transformations such as the chemistry of soil organic matter [5], the concentration and mobility of nitrogen pools [6], the microbial community structure and the root biomass $[7,8]$. Considering the differential degree of alteration of these manyfold factors, substantial discrepancies in gross nitrogen transformation fluxes have been observed as a function of the used set-up. For instance, Booth et al. [9] performed gross nitrogen transformation rates by in situ incubations using introduced soil cores in which the soil was either mixed or left intact before starting the ${ }^{15} \mathrm{~N}$ isotopic dilution experiment.

Key words: ${ }^{15} \mathrm{~N}$ labelling, ${ }^{15} \mathrm{~N}$ tracing, nitrogen transformation, soil nitrogen cycle. ${ }^{1}$ To whom correspondence should be addressed (email tobias.rutting@dpes.gu.se).
It was indicated that soil mixing promoted gross nitrogen mineralization and $\mathrm{NH}_{4}{ }^{+}$consumption [9]. Arnold et al. [10] showed that cold storage and laboratory incubation of intact soil cores resulted in a lower $\mathrm{NH}_{4}{ }^{+}$and higher $\mathrm{NO}_{3}{ }^{-}$ turnover compared to in situ incubated soil cores.

While concerns related to soil organic matter and nitrogen pools are largely surmounted when using in situ incubations of introduced soil cores $[1,11]$, most current experimental setups fail to keep the soil-microbial-root system intact [12]. The general practice of inserting cylinders before adding ${ }^{15} \mathrm{~N}$ to the soil excises roots and disturbs the exchange of resources between roots and their associated microbial communities. Altering these interactions leads to unrepresentative estimates of nitrogen availability in plant communities and an incomplete understanding of the environmental factors that control plant-available nitrogen [12]. Plant roots secrete a variety of low- and high-molecular-mass compounds into the soil as exudates [13] that influence the turnover, composition and activity of the soil microbial community [14-17]. Additionally, mycorrhizal fungi associated with plant roots alter soil nitrogen availability by competing for organic and inorganic nitrogen sources in the soil matrix [18]. Consequently, laboratory experiments that manipulated root densities and functioning have indicated the overarching influence of live roots on gross nitrogen transformations [17,19-21]. Isotope dilution methods applied to the intact soil-microbial-root system have rarely been reported. One example is the study by Templer et al. [22] which investigated nitrogen dynamics using in-growth cores in a tropical montane forest soil. However, owing to the installation of the in-growth cores 11 months before the ${ }^{15} \mathrm{~N}$ isotope dilution 
Figure 1 | Example layout of ${ }^{15} \mathrm{~N}$ labelling plot for two ${ }^{15} \mathrm{~N}$ treatments and six time steps

The square plots indicate the locations for injection of ${ }^{15} \mathrm{~N}$-enriched solution at $t_{0}$ containing either ${ }^{15} \mathrm{NH}_{4} \mathrm{NO}_{3}$ or $\mathrm{NH}_{4}{ }^{15} \mathrm{NO}_{3}$, and the circular areas within the squares indicate the 'virtual soil cores' that will be sampled at different times ( $t=$ time of soil sampling). Example distances between plots (within and between rows) and times for extraction are given, but they will depend on the actual field conditions.

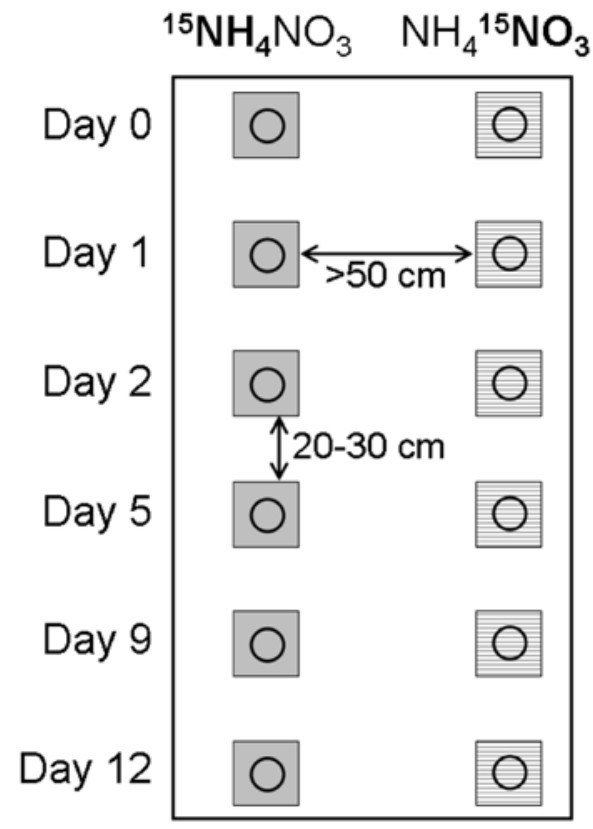

study, fine root biomass in the cores was only $59 \%$ of the background level in undisturbed soil [22].

We developed a new in situ ${ }^{15} \mathrm{~N}$ soil-labelling method, called 'virtual soil core' injection, which is based on a technique to examine the dynamics of soil amino acids (e.g. $[23,24])$, but that to our knowledge has only recently been used to study gross nitrogen transformations (J. Staelens, T. Rütting, D. Huygens, A. De Schrijver, C. Müller, K. Verheyen and P. Boeckx, unpublished work, and T. Rütting, P. Boeckx, J. Staelens and L. Klemedtsson, unpublished work). In this approach, gross nitrogen dynamics are studied under field conditions in undisturbed soils with live roots and their associated microbial communities. Within an experimental site, several representative plots (approx. $1 \mathrm{~m} \times 1.5 \mathrm{~m}$ ) are selected as replicates. For each ${ }^{15} \mathrm{~N}$ labelling treatment and time step, a $10 \mathrm{~cm} \times 10 \mathrm{~cm}$ location is prepared in each plot (Figure 1). The four corners of the location are then marked out by small sticks so that templates for nitrogen addition and soil sampling can be used later on. To study mineral forest soils, it is helpful to separate the litter and mineral layer by placing a nylon mesh on top of the mineral layer. As such, the litter layer can easily be removed during the following injection and sampling steps. To ensure that the microclimatic conditions of the labelled soils remain as intact as possible, any natural soil cover (e.g. straw in arable fields or litter layers in forests) should only be removed for ${ }^{15} \mathrm{~N}$ injection, but replaced during the incubation time until soil sampling.

For injection of ${ }^{15} \mathrm{~N}$ labelling solutions, where one of the moieties is enriched in ${ }^{15} \mathrm{~N}$ (e.g. $\mathrm{NH}_{4}{ }^{+}, \mathrm{NO}_{2}{ }^{-}$and $\mathrm{NO}_{3}{ }^{-}$), a $10 \mathrm{~cm} \times 10 \mathrm{~cm}$ template is slid over the sticks. The template contains a sufficient number of holes in order to inject the ${ }^{15} \mathrm{~N}$ enriched solutions in the studied soil layer. Hart et al. [1] recommended at least six injection locations within a soil core of $4 \mathrm{~cm}$ diameter. However, to minimize edge effects, it is advisable to inject the ${ }^{15} \mathrm{~N}$ solution into a larger area than the final sample core size (T. Rütting, P. Boeckx, J. Staelens and L. Klemedtsson, unpublished work). Similarly to isotope dilution studies, the ${ }^{15} \mathrm{~N}$ solutions should be added as uniformly as possible both horizontally and vertically [27]. Soil sampling is carried out at defined time steps after ${ }^{15} \mathrm{~N}$ injection (e.g. 15 min, 1, 2, 5, 9 and 12 days) by pushing a PVC sampling tube into the soil layer through the fitting central hole of a second template. The templates with the marking sticks are used to ensure the sampling of the ${ }^{15} \mathrm{~N}$ labelled soil. The sampled soil cores are then processed as quickly as possible (weighing, sieving and extraction) and the size and ${ }^{15} \mathrm{~N}$ content of nitrogen pools are determined (e.g. $\mathrm{NH}_{4}{ }^{+}$, $\mathrm{NO}_{3}{ }^{-}$and organic nitrogen). To quantify potential nitrogen losses during the field experiment in the open 'virtual' soil cores, it is recommended to measure the size and ${ }^{15} \mathrm{~N}$ content of total soil nitrogen at the different time points.

\section{Numerical data analysis}

In ${ }^{15} \mathrm{~N}$ labelling experiment, gross soil nitrogen dynamics are typically determined by analytically solved equations with data from ${ }^{15} \mathrm{~N}$ dilution experiments. The ${ }^{15} \mathrm{~N}$ isotope dilution model of Kirkham and Bartholomew [28] is applied to determine the gross rates between two nitrogen pools. For this analysis, it is assumed that (i) no isotopic fractionation occurs during microbial transformations of soil nitrogen, (ii) no remineralization of added ${ }^{15} \mathrm{~N}$ takes place and (iii) nitrogen transformation rates are usually assumed to be constant [1], although first-order models have also be developed (e.g. [29]). Thus analytical equations can most realistically only be applied for short-term incubations when remineralization is negligible [30-32]. Moreover, analytical solutions do actually quantify only the total gross production and consumption of the labelled pool and do not provide information on gross rates for specific processes [33].

To overcome the limitations of analytical solutions, it was recommended to use a numerical data analysis via socalled ${ }^{15} \mathrm{~N}$-tracing models $[32,34,35]$. Barraclough and Puri [36] used such an approach to separate $\mathrm{NO}_{3}{ }^{-}$production, quantified by an analytical model, into heterotrophic and autotrophic nitrification pathways. Generally, numerical approaches combine the principles of the ${ }^{15} \mathrm{~N}$ dilution, where a product pool is labelled, with ${ }^{15} \mathrm{~N}$-tracing techniques, where a substrate pool is labelled and the movement of the isotope is followed in various product pools over a longer time period [1]. These ${ }^{15} \mathrm{~N}$-tracing models consist of at least three nitrogen pools $\left(\mathrm{NH}_{4}{ }^{+}, \mathrm{NO}_{3}{ }^{-}\right.$and organic nitrogen) and 
Figure 2 Example of a conceptual ${ }^{15} \mathrm{~N}$-tracing model to analyse gross nitrogen transformation rates

The considered pools in this example are ammonium $\left(\mathrm{NH}_{4}{ }^{+}\right)$, nitrate $\left(\mathrm{NO}_{3}{ }^{-}\right)$as well as two organic nitrogen pools (labile $\mathrm{N}_{\text {lab }}$ and more recalcitrant $\mathrm{N}_{\text {rec }}$ ). Eight nitrogen transformations are considered: mineralization of labile and recalcitrant organic nitrogen ( $M_{\text {Nlab }}$ and $\left.M_{\mathrm{Nrec}}\right)$, immobilization of $\mathrm{NH}_{4}{ }^{+}\left(I_{\mathrm{NH} 4 \rightarrow \mathrm{Nlab}}\right.$ and $\left.I_{\mathrm{NH} 4 \rightarrow \mathrm{Nrec}}\right)$ and of $\mathrm{NO}_{3}{ }^{-}$ $\left(I_{\mathrm{NO} 3}\right)$, oxidation of $\mathrm{NH}_{4}+\left(\mathrm{O}_{\mathrm{NH} 4}\right)$ and organic nitrogen $\left(\mathrm{O}_{\mathrm{Nrec}}\right)$ to $\mathrm{NO}_{3}{ }^{-}$ as well as dissimilatory $\mathrm{NO}_{3}{ }^{-}$reduction to $\mathrm{NH}_{4}{ }^{+}\left(D_{\mathrm{NO} 3}\right)$. Modified from Soil Biology and Biochemistry, vol. 39, C. Müller, T. Rütting, J. Kattge, R.J., Laughlin and R.J. Stevens, Estimation of parameters in complex ${ }^{15} \mathrm{~N}$ tracing models via Monte Carlo sampling, pp. 715-726, (C) 2007, with permission from Elsevier.

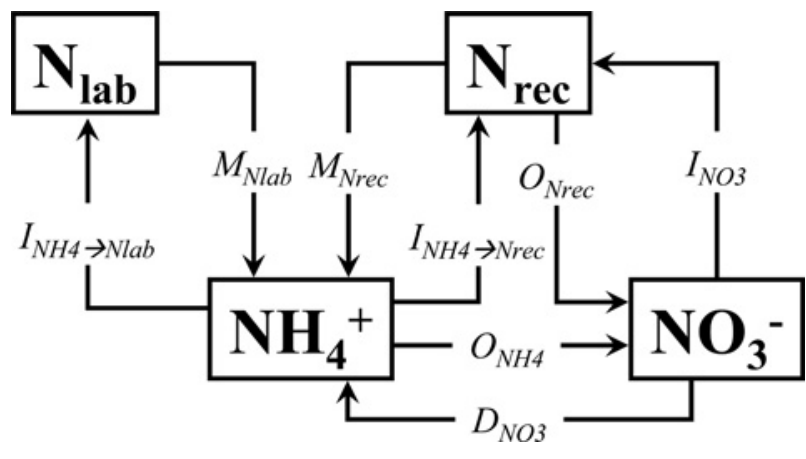

various nitrogen transformations that simultaneously transfer nitrogen between the pools. Process-specific gross rates for the nitrogen transformations can be quantified via nonlinear optimization routines [35,37]. However, ${ }^{15} \mathrm{~N}$-tracing models often face the problem of over-parameterization [35], for which reason only a low number of nitrogen processes and simple kinetic settings (e.g. no MichaelisMenten kinetics) can be considered $[35,37,38]$. To apply more complex, and hence probably more realistic, ${ }^{15} \mathrm{~N}$-tracing models, a robust optimization technique, not limited by the degree of freedom, was developed based on Monte Carlo sampling techniques (Figure 2, [37]). It was shown that this ${ }^{15} \mathrm{~N}$ analysis tool was able to reliably quantify a range of gross nitrogen transformation rates, with the additional benefit that a suitable kinetic setting could be implemented (i.e. consideration of Michaelis-Menten kinetics if appropriate).

Applying this novel ${ }^{15} \mathrm{~N}$ methodology helped us to deepen our understanding of specific pathways within the soil nitrogen cycle. Experiments in grassland soils have revealed more insight into gross nitrogen dynamics in conjunction with nitrite $\left(\mathrm{NO}_{2}{ }^{-}\right)$dynamics, a precursor of nitrous oxide, indicating the importance of oxidation of organic nitrogen for the soil $\mathrm{NO}_{2}{ }^{-}$pool [39]. For a pristine forest soil, Rütting et al. [40] showed that dissimilatory $\mathrm{NO}_{3}{ }^{-}$ reduction to $\mathrm{NH}_{4}{ }^{+}$(DNRA) was a more important $\mathrm{NO}_{3}{ }^{-}$consumption process than denitrification. Applying the virtual soil core approach indicated the importance of heterotrophic nitrification (oxidation of organic nitrogen to $\mathrm{NO}_{3}{ }^{-}$) in forest soils (J. Staelens, T. Rütting, D. Huygens, A. De Schrijver, C. Müller, K. Verheyen and P. Boeckx, unpublished work). The use of the virtual soil core set-up might have been crucial in this study, since soil disturbing processes such as sieving or delimiting soil cores have been observed to disrupt the functioning of heterotrophic nitrifiers such as soil fungi $[41,42]$.

\section{Advantages and drawbacks}

The first advantage of the described ${ }^{15} \mathrm{~N}$ application and numerical analysis methods is that the obtained gross nitrogen dynamics are representative of the actual field conditions because the soil-microbial-root system is only marginally disturbed. Hence, soil properties are not changed, and heat, nutrients and gas can exchange according to actual field conditions. Nevertheless, short-term ${ }^{15} \mathrm{~N}$ labelling studies face the problem that nitrogen transformations can be altered as a result of the ${ }^{15} \mathrm{~N}$ addition itself, as the mineral soil nitrogen and the water contents are increased. It is therefore recommended to add only small amounts of highly enriched ${ }^{15} \mathrm{~N}$ solutions [1]. The potential stimulation of the production and consumption rates by adding inorganic nitrogen will be greatest at the start of an experiment. As the rates are averaged over time, this drawback is largely compensated by the fact that the ${ }^{15} \mathrm{~N}$-tracing approach with numerical data analysis allows longer study periods (1-2 weeks) than in common isotope dilution experiments with analytical data analysis (usually 1-2 days). The second advantage is that a numerical ${ }^{15} \mathrm{~N}$-tracing model provides information on many simultaneously occurring gross nitrogen transformation rates. This clearly increases our understanding of soil nitrogen dynamics because the contribution of specific nitrogen transformation pathways to the total production and consumption of organic and inorganic nitrogen pools can be quantified.

The numerical ${ }^{15} \mathrm{~N}$-tracing analysis requires, however, more time steps and thus more chemical analyses of soil samples in comparison with the ${ }^{15} \mathrm{~N}$ isotope dilutions. This has earlier been discussed as an disadvantage of the tracing techniques [34]. Additionally, the inherent soil heterogeneity may result in a high variation in gross nitrogen cycling fluxes between replicate samples (e.g. [43]), for which a high number of spatial replicates in the field should be taken.

The nitrogen transformation rates obtained depend, among other things, on the actual soil temperature, moisture and microclimatic conditions during the study. Precipitation during the experimental period should be controlled, since changes in soil moisture will affect microbial activity and nitrogen process rates. The dependency on actual soil conditions implies that the comparison of nitrogen dynamics between sites or treatments should occur as synchronized as possible. This requires appropriate coordination during field campaigns.

Similarly to classical ${ }^{15} \mathrm{~N}$ experiments, there could be an incomplete recovery of ${ }^{15} \mathrm{~N}$ in the sampled soil due to various processes, including gaseous nitrogen loss through ammonia volatilization or denitrification, uptake and transport of inorganic nitrogen by roots and mycorrhizae, leaching of dissolved nitrogen below the sampled soil, and diffusion of 
injected ${ }^{15} \mathrm{~N}$ to non-labelled soil around the sampled virtual cores. In order to quantify nitrogen loss pathways in the tracing model, the ${ }^{15} \mathrm{~N}$ content of the bulk soil should be analysed (J. Staelens, T. Rütting, D. Huygens, A. De Schrijver, C. Müller, K. Verheyen and P. Boeckx, unpublished work). The inflow of unlabelled mineral nitrogen via passive or active transport processes may lead to an overestimation of the gross nitrogen production fluxes. This diffusion can be accounted for by injecting ${ }^{15} \mathrm{~N}$ into an edge zone around the sampled soil (T. Rütting, P. Boeckx, J. Staelens and L. Klemedtsson, unpublished work).

\section{Conclusions}

It is concluded that the presented methodology has the potential to increase our understanding in gross nitrogen cycling studies that focus on the soil-microbial-root system. The incorporation of these methodologies into ecosystem biogeochemistry will allow discerning the importance of rhizosphere nitrogen transformation pathways other than the classical mineralization-immobilization turnover.

\section{Funding}

T.R. was supported by the NitroEurope IP under the European Commission Sixth Framework Programme [contract number 017841]. D.H. and J.S. were funded as postdoctoral fellows by the Research Foundation-Flanders (FWO). A Short Visit Grant of the European Science Foundation Nitrogen in Europe (NinE) research network was granted to J.S.

\section{References}

1 Hart, S.C., Stark, J.M., Davidson, E.A. and Firestone, M.K. (1994) Nitrogen mineralization, immobilization, and nitrification. In Methods of Soil Analysis Part 2: Microbiological and Biochemical Properties (Weaver, R.W., Angle, S., Bottomley, P., Bezdicek, D., Smith, S., Tabatai, A. and Wollum, A., eds), pp. 985-1018, Soil Science Society of America, Madison

2 Zak, D.R., Holmes, W.E., Finzi, A.C. and Norby, R.J. (2003) Soil nitrogen under elevated $\mathrm{CO}_{2}$ : a synthesis of forest face experiments. Ecol. Appl. 13, 1508-1514

3 Corre, M.D., Brumme, R., Veldkamp, E. and Beese, F.O. (2007) Changes in nitrogen cycling and retention processes in soils under spruce forests along a nitrogen enrichment gradient in Germany. Global Change Biol. 13, 1509-1527

4 Huygens, D., Boeckx, P., Templer, P., Paulino, L., Van Cleemput, 0., Oyarzún, C., Müller, C. and Godoy, R. (2008) Mechanisms for retention of bioavailable nitrogen in volcanic rainforest soils. Nat. Geosci. 1, 543-548

5 Meier, C.L. and Bowman, W.D. (2008) Links between plant litter chemistry, species diversity, and below-ground ecosystem function. Proc. Natl. Acad. Sci. U.S.A. 105, 19780-19785

6 Schimel, J.P. and Bennett, J. (2004) Nitrogen mineralization: challenges of a changing paradigm. Ecology 85, 591-602

7 jackson, L.E., Burger, M. and Cavagnaro, T.R. (2008) Roots, nitrogen transformations and ecosystem services. Annu. Rev. Plant Biol. 59 341-363

8 Zak, D. R., Holmes, W. E., White, D. C., Peacock, A. D. and Tilman, D. (2003) Plant diversity, soil microbial communities, and ecosystem function: are there any links? Ecology 84, 2042-2050

9 Booth, M.S., Stark, J.M. and Hart, S.C. (2006) Soil-mixing effects on inorganic nitrogen production and consumption in forest and shrubland soils. Plant Soil $\mathbf{2 8 9}, 5-15$
10 Arnold, J., Corre, M.D. and Veldkamp, E. (2008) Cold storage and laboratory incubation of intact soil cores do not reflect in-situ nitrogen cycling rates of tropical forest soils. Soil Biol. Biochem. 40, 2480-2483

11 Davidson, E.A., Hart, S.C., Shanks, C.A. and Firestone, M.K. (1991) Measuring gross nitrogen mineralization, immobilization, and nitrification by ${ }^{15} \mathrm{~N}$ isotopic pool dilution in intact soil cores. J. Soil Sci. 42, 335-349

12 Frank, D.A. and Groffman, P.M. (2009) Plant rhizospheric N processes: what we don't know and why we should care. Ecology 90, 1512-1519

13 Lynch, J.M. and Whipps, J.M. (1990) Substrate flow in the rhizosphere. Plant Soil 129, 1-10

14 Bird, J.A., Herman, D.J. and Firestone, M.K. (2010) Rhizosphere priming of soil organic matter by bacterial groups in a grassland soil. Soil Biol. Biochem., doi:10.1016/j.soilbio.2010.08.010

15 Semenov, A.M., van Bruggen, A.H.C. and Zelenev, V.V. (1999) Moving waves of bacterial populations and total organic carbon along roots of wheat. Microb. Ecol. 37, 116-128

16 Alphei, J., Bonkowski, M. and Scheu, S. (1996) Protozoa, Nematoda and Lumbricidae in the rhizosphere of Hordelymus europoeus (Poaceae): faunal interactions, response of microorganisms and effects on plant growth. Oecologia 106, 111-126

17 Cheng, W. (2009) Rhizosphere priming effect: its functional relationships with microbial turnover, evapotranspiration, and $\mathrm{C}-\mathrm{N}$ budgets. Soil Biol. Biochem. 41, 1795-1801

18 Smith, S.E. and Read, D.J. (2008) Mycorrhizal Symbiosis, Academic Press, San Diego

19 Burger, M. and Jackson, L.E. (2004) Plant and microbial use and turnover: rapid conversion of nitrate to ammonium in soil with roots. Plant Soil 266, 289-301

20 Herman, D.J., Johnson, K.K., Jaeger, III, C.H., Schwartz, E. and Firestone, M.K. (2006) Root influence on nitrogen mineralization and nitrification in Aveno barbato rhizosphere soil. Soil Sci. Soc. Am. J. 70, 1504-1511

21 Norton, J.M. and Firestone, M.K. (1996) N dynamics in the rhizosphere of Pinus ponderoso seedlings. Soil Biol. Biochem. 28, 351-362

22 Templer, P.H., Silver, W.L., Pett-Ridge, J., DeAngelis, K.M. and Firestone, M.K. (2008) Plant and microbial controls on nitrogen retention and loss in a humid tropical forest. Ecology 89, 3030-3040

23 Andresen, L.C., Jonasson, S., Ström, L. and Michelsen, A. (2008) Uptake of pulse injected nitrogen by soil microbes and mycorrhizal and non-mycorrhizal plants in a species-diverse subarctic heath ecosystem. Plant Soil 313, 283-295

24 Gallet-Budynek, A., Brzostek, E., Rodgers, V.L., Talbot, J., Hyzy, S. and Finzi, A.C. (2009) Intact amino acid uptake by northern hardwood and conifer trees. Oecologia 160, 129-138

25 Reference deleted

26 Reference deleted

27 Luxhøi, J., Nielsen, N.E. and Jensen, L.S. (2003) Influence of ${ }^{15} \mathrm{NH}_{4}{ }^{+}$-application on gross $\mathrm{N}$ turnover rates in the soil. Soil Biol. Biochem. 35, 603-606

28 Kirkham, D. and Bartholomew, W.V. (1954) Equations for following nutrient transformations in soil, utilizing tracer data. Soil Sci. Soc. Am. Ргос. 18, 33-34

29 Kirkham, D. and Bartholomew, W.V. (1955) Equations for following nutrient transformations in soil, utilizing tracer data: II. Soil Sci. Soc. Am. Proc. 19, 189-192

30 Smith, C.J., Chalk, P.M., Crawford, D.M. and Wood, J.T. (1994) Estimating gross nitrogen mineralization and immobilization rates in anaerobic and aerobic soil suspensions. Soil Sci. Soc. Am. J. 58, 1652-1660

31 Takahashi, S. (2001) Comparison of gross nitrogen mineralization rates by zero-order models. Soil Sci. Soc. Am. J. 65, 244-246

32 Bjarnason, S. (1988) Calculation of gross nitrogen immobilization and mineralization in soil. J. Soil Sci. 39, 393-406

33 Schimel, J. (1996) Assumptions and errors in the ${ }^{15} \mathrm{NH}_{4}+$ pool dilution technique for measuring mineralization and immobilization. Soil Biol. Biochem. 28, 827-828

34 Nason, G.E. and Myrold, D.D. (1991) ${ }^{15} \mathrm{~N}$ in soil research: appropriate application of rate estimation procedures. Agric. Ecosyst. Environ. $\mathbf{3 4}$ 427-441

35 Rütting, T. and Müller, C. (2007) ${ }^{15} \mathrm{~N}$ tracing models with a Monte Carlo optimization procedure provide new insights on gross $\mathrm{N}$ transformations in soil. Soil Biol. Biochem. 39, 2351-2361

36 Barraclough, D. and Puri, G. (1995) The use of ${ }^{15} \mathrm{~N}$ pool dilution and enrichment to separate the heterotrophic and autotrophic pathways of nitrification. Soil Biol. Biochem. 27, 17-22 
37 Müller, C., Rütting, T., Kattge, J., Laughlin, R.J. and Stevens, R.J. (2007) Estimation of parameters in complex ${ }^{15} \mathrm{~N}$ tracing models via Monte Carlo sampling. Soil Biol. Biochem. 39, 715-726

38 Myrold, D.D. and Tiedje, J.M. (1986) Simultaneous estimation of several nitrogen cycle rates using ${ }^{15} \mathrm{~N}$ : theory and application. Soil Biol. Biochem. 18, 559-568

39 Rütting, T. and Müller, C. (2008) Process-specific analysis of nitrite dynamics in a permanent grassland soil by using a Monte Carlo sampling technique. Eur. J. Soil Sci. 59, 208-215

40 Rütting, T., Huygens, D., Müller, C., Van Cleemput, 0., Godoy, R. and Boeckx, P. (2008) Functional role of DNRA and nitrite reduction in a pristine south Chilean Nothofogus forest. Biogeochemistry 90, 243-258
41 Bengtsson, G., Bengtson, P. and Månsson, K.F. (2003) Gross nitrogen mineralization-, immobilization-, and nitrification rates as function of soil C/N ratio and microbial activity. Soil Biol. Biochem. 35, 143-154

42 de Vries, F.T., Bååth, E., Kuyper, T.W. and Bloem, J. (2009) High turnover of fungal hyphae in incubation experiments. FEMS Microbiol. Ecol. 67 389-396

43 Corre, M.D., Schnabel, R.R. and Stout, W.L. (2002) Spatial and seasonal variation of gross nitrogen ransformations and microbial biomass in a northeastern US grassland. Soil Biol. Biochem. 34, 445-457

Received 14 September 2010

doi:10.1042/BST0390279 